Article

\title{
Simple Synthesis of Cobalt Carbonate Hydroxide Hydrate and Reduced Graphene Oxide Hybrid Structure for High-Performance Room Temperature $\mathrm{NH}_{3}$ Sensor
}

\author{
Chang Wang ${ }^{1,3}\left(\mathbb{C}\right.$, Huan Wang ${ }^{1}$, Dan Zhao ${ }^{1}$, Xianqi Wei ${ }^{1,4}$, Xin $\mathrm{Li}^{1,3, *}$, Weihua Liu ${ }^{1,3}{ }^{1}$ and \\ Hongzhong Liu ${ }^{2}$ \\ 1 Department of Microelectronics, School of Electronics and Information Engineering, Xi'an Jiaotong \\ University, Xi'an 710049, China; wangc254@163.com (C.W.); wanghuan19960511@stu.xjtu.edu.cn (H.W.); \\ zhaodan_xjtu@163.com (D.Z.); wei.wxq@163.com (X.W.); lwhua@mail.xjtu.edu.cn (W.L.) \\ 2 State Key Laboratory for Manufacturing Systems Engineering, Xi'an Jiaotong University, Xi'an 710049, \\ China; hzliu@mail.xjtu.edu.cn \\ 3 Guangdong Shunde Xi'an Jiaotong University Academy, NO.3 Deshengdong Road, Daliang, \\ Shunde District, Foshan 528300, China \\ 4 Research Institute of Xi'an Jiaotong University, No. 328 Wenming Road, Xiaoshan District, \\ Hangzhou 311215, China \\ * Correspondence: 1x@mail.xjtu.edu.cn; Tel.: +86-29-82663343
}

Received: 21 December 2018; Accepted: 29 January 2019; Published: 1 February 2019

\begin{abstract}
A novel hybrid structure sensor based on cobalt carbonate hydroxide hydrate $(\mathrm{CCHH})$ and reduced graphene oxide (RGO) was designed for room temperature $\mathrm{NH}_{3}$ detection. This hybrid structure consisted of CCHH and RGO (synthesized by a one-step hydrothermal method), in which RGO uniformly dispersed in $\mathrm{CCHH}$, being used as the gas sensing film. The resistivity of the hybrid structure was highly sensitive to the changes on $\mathrm{NH}_{3}$ concentration. $\mathrm{CCHH}$ in the hybrid structure was the sensing material and RGO was the conductive channel material. The hybrid structure could improve signal-to-noise ratio (SNR) and the sensitivity by obtaining the optimal mass proportion of RGO, since the proportion of RGO was directly related to sensitivity. The gas sensor with $0.4 \mathrm{wt} \%$ RGO showed the highest gas sensing response reach to $9 \%$ to $1 \mathrm{ppm} \mathrm{NH}_{3}$. Compared to a conventional gas sensor, the proposed sensor not only showed high gas sensing response at room temperature but also was easy to achieve large-scale production due to the good stability and simple synthesis process.
\end{abstract}

Keywords: gas sensor; cobalt carbonate hydroxide hydrate; reduced graphene oxide; room temperature; ammonia

\section{Introduction}

As an irritating odor and highly toxic gas, ammonia is widely found in industrial exhaust emissions, which is gradually threatening the health of humans and animals. Therefore, it is very crucial to develop highly sensitivity ammonia sensors and detection equipment.

Semiconductor gas sensors, all using metal oxide semiconductors as sensing materials, are widely applied to detect various gases owing to the good repeatability and low cost [1-3]. Xu et al. have adjusted the aspect ratio of $\mathrm{In}_{2} \mathrm{O}_{3}$ nanowires to prepare gas sensors with a great gas sensing properties to $\mathrm{NO}_{2}$ [4]. The $\mathrm{SnO}_{2}$ nanowire had good gas sensing properties for hydrogen [5]. Wagh et al. used modified $\mathrm{ZnO}$ thick film to prepare a highly sensitivity ammonia sensor [6]. In order to further improve the gas sensing properties, there were two research ideas in the academic circles all 
over the world. The first one was to increase the specific surface area of sensing materials by preparing porous materials, which could improve the gas sensing properties by providing more gas adsorption sites on the sensing materials surface $[7,8]$. The other was to prepare composite film gas sensors based on the excellent conductivity of graphene and the gas sensitivity of metal oxides $[9,10]$. Considering the high mobility and conductivity of graphene, the latter method has attracted increasing attentions from the gas sensors field.

In recent years, many works on gas sensors based on composite structures of graphene and sensing materials have been published [11-17]. RGO decorated $\mathrm{TiO}_{2}$ microspheres was fabricated by a hydrothermal method and showed excellent sensitivity and good selectivity to ammonia gas [16]. Feng et al. prepared an evenly dispersed $\mathrm{RGO}-\mathrm{SnO}_{2}$ composite sensor by mixing the RGO obtained from thermal reduction with the commercial $\mathrm{SnO}_{2}$ nanoparticles. Although the sensor had good gas sensing properties at room temperature, its noise was very high [17]. Liu et al. has grown $\mathrm{ZnO}$ nanowalls on the RGO surface to realize a gas sensor with composite structure, which has realized the detection of nitrogen dioxide at room temperature [18].

Combining with the previous research, a new research idea has been gradually produced recently, which is to synthesize the ideas proposed above so as to further improve the gas sensing properties. $\mathrm{ZnO}$ nanoparticles loaded onto 3D RGO with hydrothermal method was very sensitive to CO [19]. Liu et al. prepared a flower-like morphology of $\mathrm{ZnO}$ in order to provide more gas adsorption sites by increasing the specific surface area and designed a flower-like $\mathrm{ZnO}$ with RGO composite structure, which could detect ultra-low concentrations of nitrogen dioxide gas [20]. However, most of the sensors mentioned above must have good gas sensing properties in the temperature range of $200-300{ }^{\circ} \mathrm{C}$. Although a few sensors could detect target gas at room temperature, the gas sensing properties were not good enough and the synthetic processes were relatively complex.

Cobalt carbonate hydroxide hydrate $\left(\mathrm{Co}\left(\mathrm{CO}_{3}\right)_{0.5} \mathrm{OH} \bullet 0.11 \mathrm{H}_{2} \mathrm{O}\right)$, referred as $\mathrm{CCHH}$ has been usually utilized as the precursor to obtain $\mathrm{Co}_{3} \mathrm{O}_{4}$ by annealing process at $300-500{ }^{\circ} \mathrm{C}$ [21-23]. $\mathrm{CCHH}$ has the potential to become a promising gas sensing material due to its simple synthesis process, high specific surface area and large three-dimensional space. However, to the best of our knowledge, no work has been reported on the use of $\mathrm{CCHH}$ as an efficient gas sensing material. The reason $\mathrm{CCHH}$ has not used as a sensing material before is the low conductivity of $\mathrm{CCHH}$ as the intrinsic limitation for its gas sensing application. Therefore, improving its conductivity is extremely critical for $\mathrm{CCHH}$ used in the gas sensing field. A favorable way to overcome this problem is to incorporate $\mathrm{CCHH}$ with high conductivity materials in a proper manner, which can efficiently facilitate the electron transport and improve the gas sensing properties.

This paper proposed a novel hybrid structure sensor based on CCHH and RGO, designed for room temperature $\mathrm{NH}_{3}$ detection. The hybrid structure consisted of $\mathrm{CCHH}$ and $\mathrm{RGO}$, in which $\mathrm{CCHH}$ was designed as a gas sensing material and RGO as a conductive material. We expected to achieve the improvement of SNR and the sensitivity by obtaining the optimal proportion of RGO, because the proportion of RGO in the hybrid structure was directly related to the sensitivity.

\section{Materials and Methods}

\subsection{Preparation of $\mathrm{CCHH}$ with $\mathrm{RGO}$}

GO (20 mg, \#XF002-1, XF Nano Inc., Nanjing, China) was dispersed in deionized water (60 mL), vibrated and sonicated for $4 \mathrm{~h}$. After GO dispersed evenly in the solution, cobalt chloride hexahydrate (20 mmol, \#20160823, Guangdong Guanghua Sic-Tech Co., Ltd., Shantou, China) and urea (20 mmol, Tianli Chemical Reagent Co. Ltd., Tianjin, China) were added into the dispersed solution, stirred and sonicated for $3 \mathrm{~min}$. When the two chemicals were completely dissolved and evenly distributed in the solution, the solution was transferred into a reaction kettle to conduct hydrothermal reactions for $3 \mathrm{~h}$ under $130^{\circ} \mathrm{C}$. The solution fabricated by hydrothermal reaction was centrifuged and washed with deionized water several times. The obtained material was dried in oven under $60{ }^{\circ} \mathrm{C}$ for $12 \mathrm{~h}$ 
and the final product was obtained. The fabrication process of $\mathrm{CCHH}$ with RGO hybrid structure was shown in Figure 1. For comparative experiments, GO was processed in the same experimental procedure without cobalt chloride hexahydrate and urea. The results of the two experiments were attentively compared.

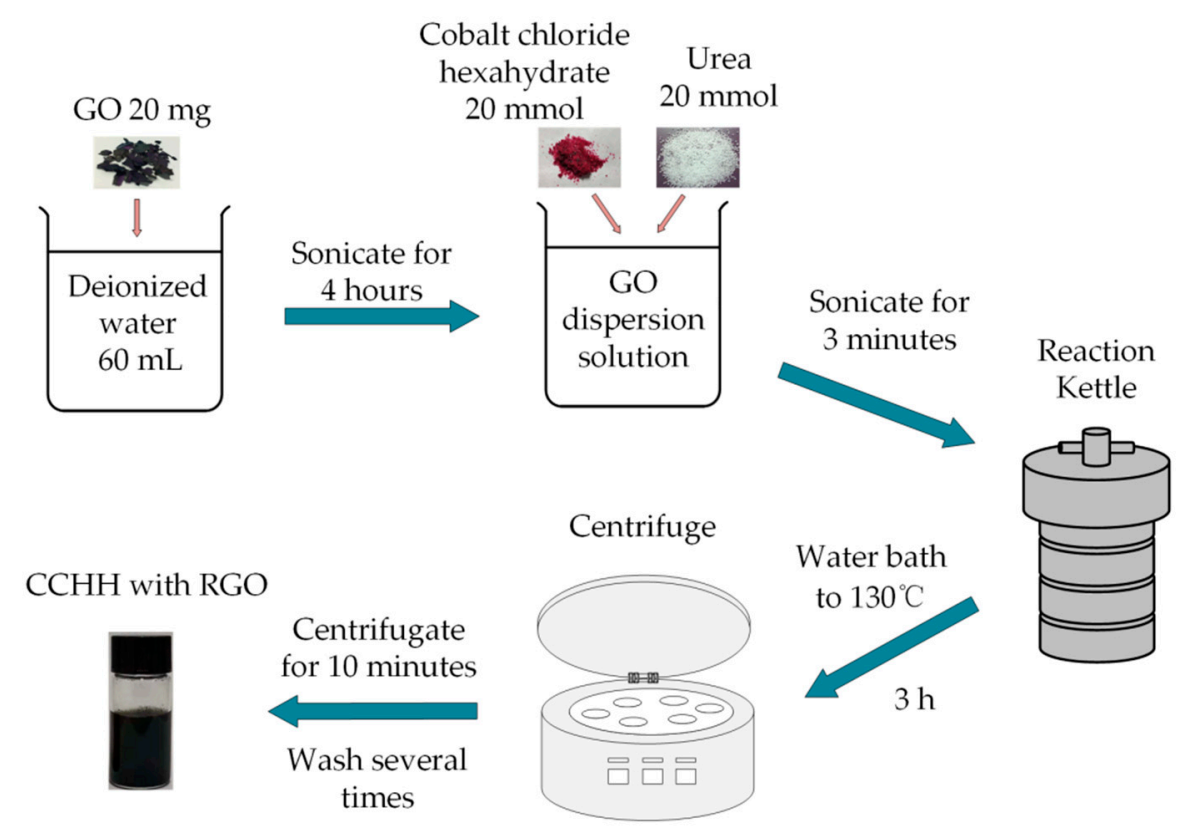

Figure 1. Fabrication flowchart of cobalt carbonate hydroxide hydrate $(\mathrm{CCHH})$ with RGO hybrid structure.

\subsection{Fabrication of CCHH-RGO Gas Sensor}

The previously cleaned target solution mainly being $\mathrm{CCHH}$ with RGO hybrid material, was transferred onto the fresh interdigital electrode (IDE) and heated in oven under $50{ }^{\circ} \mathrm{C}$ for $10 \mathrm{~min}$ and then the gas sensor named as CCHH-RGO was obtained.

In order to obtain the highest sensing response, the effect of the proportion of RGO in the hybrid structure on gas sensing response has been studied. According to the different RGO proportion, several gas sensors with different RGO mass proportion were fabricated at the same time and listed in Table 1.

Table 1. Relationship of sensor name and sensing material.

\begin{tabular}{ccccccc}
\hline Sensors & CCHH & CCHH-RGO-0.1 & CCHH-RGO-0.4 & CCHH-RGO-4 & CCHH-RGO-16 & RGO \\
\hline $\begin{array}{c}\text { Mass proportion of } \\
\text { RGO/CCHH (wt } \%)\end{array}$ & 0 & 0.1 & 0.4 & 4 & 16 & 100 \\
\hline
\end{tabular}

\subsection{Material Characterization}

The structure and morphology of CCHH-RGO were investigated with scanning electron microscopy (SEM, S-4800, Hitachi, Tokyo, Japan). X-ray photoelectron spectroscopy (XPS, Axis Ultra DLD, Kratos Inc., Manchester, UK) and X-ray diffraction (XRD, XRD-6100, Shimadzu Corporation, Kyoto, Japan) were used to characterize the elemental composition and state of the composites, respectively.

\subsection{Gas Sensing Detection}

The whole ammonia gas sensing system was based on the homemade testing chamber shown in Figure 2 and the total volume of the system was calculated as $4.67 \mathrm{~L}$. Desiccant in the flask was sodium hydroxide used to convert ammonia solution into dry ammonia gas, which was passed into the testing chamber by an air pump (MEDOVP0125-V1005-P2-1411, Nitto Kohki, Tokyo, Japan). The calculation details of dry ammonia gas concentration were included in the Supplementary Materials (SM). The test 
results were recorded by the multimeter (2000, Keithley Instruments, Cleveland, OH, USA). The entire test experiment was carried out at the temperature of $25 \pm 2{ }^{\circ} \mathrm{C}$ and the humidity of $30 \pm 5 \%$.

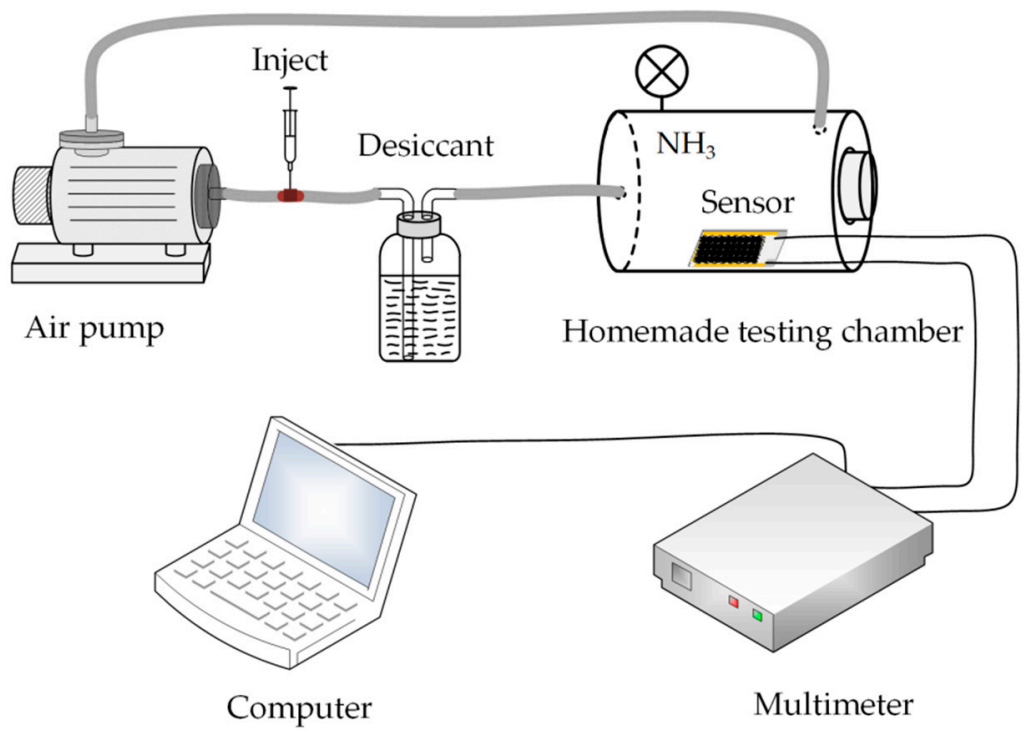

Figure 2. Schematic diagram of the gas detection system.

\section{Results and Discussion}

\subsection{Characterization of Sensing Materials}

The structure and morphology of the synthesized CCHH-RGO was characterized by various instruments. Considering the influence of different RGO proportion on the structure and gas sensing properties, CCHH-RGO-0.4 with the optimized gas sensitivity was systematically characterized as a typical one.

Figure 3a illustrated a SEM image of CCHH-RGO-0.4, revealing the 3-dimensional (3D) CCHH connected to each other by RGO. The enlarged image showed a sisal-like structure in Figure 3b, which could provide airflow pathway and large adsorption surface area of gas molecules. Therefore, $\mathrm{CCHH}$ was a very suitable candidate for gas adsorption material in terms of its 3D structure. Although the proportion of RGO was very low, it could be clearly seen that RGO shown in the white square in Figure 3a was uniformly distributed on the surface of $\mathrm{CCHH}$. In such a structure, uniformly dispersed RGO helped CCHH achieve rapid charge transfer. To investigate the composition of the obtained sample, the XRD pattern of CCHH-RGO-0.4 was shown in Figure 3c. All of these characteristic peaks in the pattern were well indexed to cobalt carbonate hydroxide hydrate (JCPDS No. 48-0084). No peaks of other impurities such as $\mathrm{Co}_{3} \mathrm{O}_{4}$ were detected in the sample pattern, meaning that high purity $\mathrm{CCHH}$ was well synthesized in the RGO dispersed solution with the hydrothermal method.

For further characterization, we performed XPS analysis of CCHH-RGO-0.4 to further investigate the chemical composition of the sample. The Co 2 p spectrum displayed two major peaks with the Binding energy (BE) values at 781.2 and $797.1 \mathrm{eV}$ in the Figure 4a, which was well matched with the Co 2p3/2 and Co 2p1/2 peaks, respectively [24,25]. Meanwhile, two sub-peaks observed beside the main peaks at 785.8 and $803 \mathrm{eV}$ in the spectrum clearly indicated the existence of $\mathrm{Co}^{2+}$ in the sample. Data from XPS and XRD showed that CCHH-RGO-0.4 was mainly composed of $\mathrm{Co}^{2+}$. The existence of sub-peaks in the spectra further revealed that $\mathrm{Co}^{2+}$ was not oxidized to the $\mathrm{Co}_{3} \mathrm{O}_{4}$, which well matched the research results by Varghese [26]. The C 1s peak of the sample at $284.9 \mathrm{eV}$ in the Figure $4 \mathrm{~b}$ was divided into a group of peaks, which mainly included C-C, C-OH, C-O-C and $\mathrm{CO}_{3}{ }^{2-}$ at 284.9, 286.5, 287.1 and $289.7 \mathrm{eV}$, separately. Combined with the C 1s peaks of the sample and GO, we concluded that GO was completely reduced to RGO due to the drastic reduction of oxygen-containing functional 
groups such as $\mathrm{C}-\mathrm{OH}$ and C-O-C. Meanwhile, the new peak appearing at 289.7 represented presence of $\mathrm{CO}_{3}{ }^{2-}$, which was mainly derived from the formation of $\mathrm{CCHH}$.
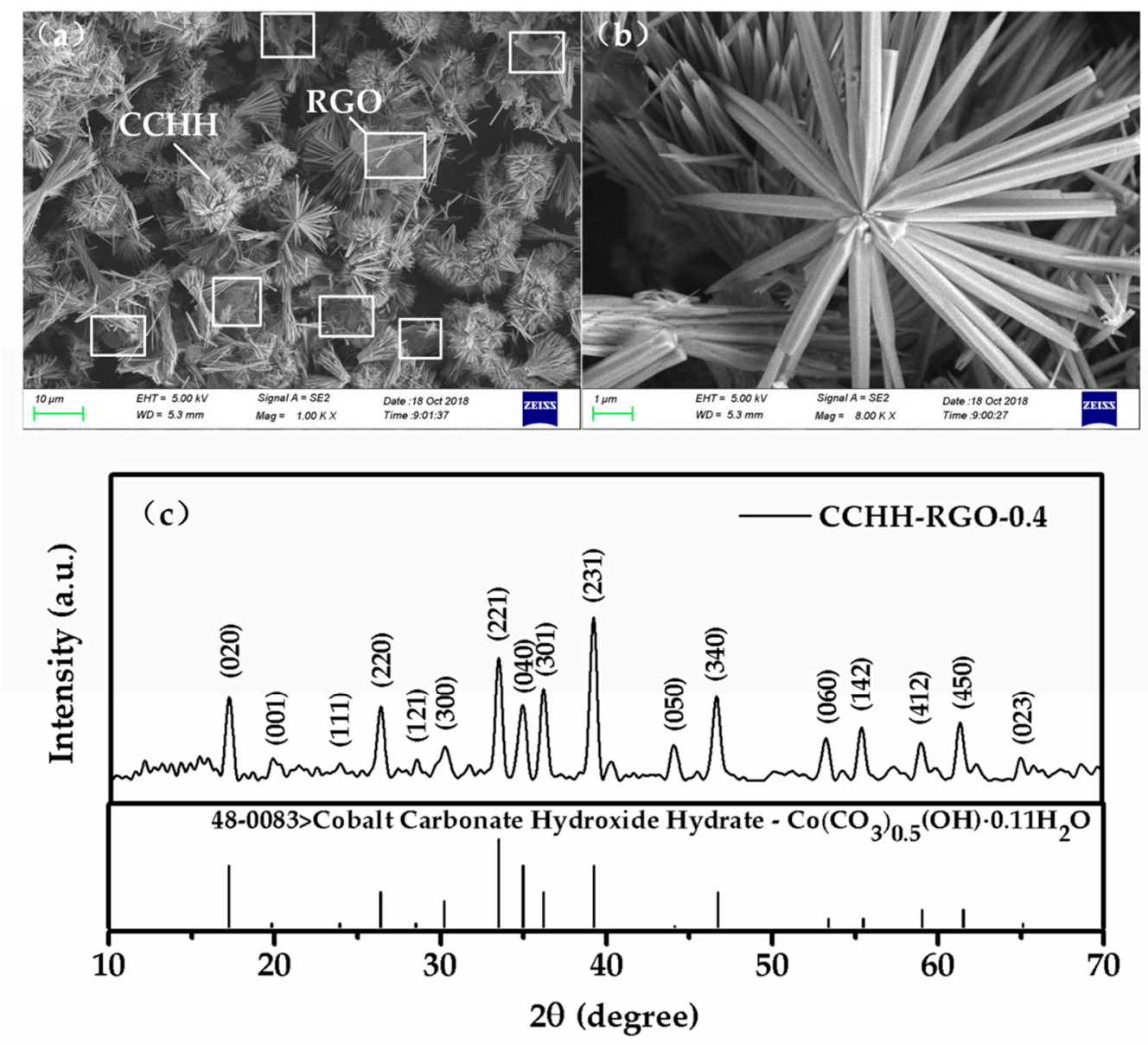

Figure 3. (a) Scanning electron microscope (SEM) image of CCHH-RGO-0.4; (b) the enlarged SEM image of CCHH-RGO-0.4; (c) X-ray diffraction (XRD) pattern of CCHH-RGO-0.4.
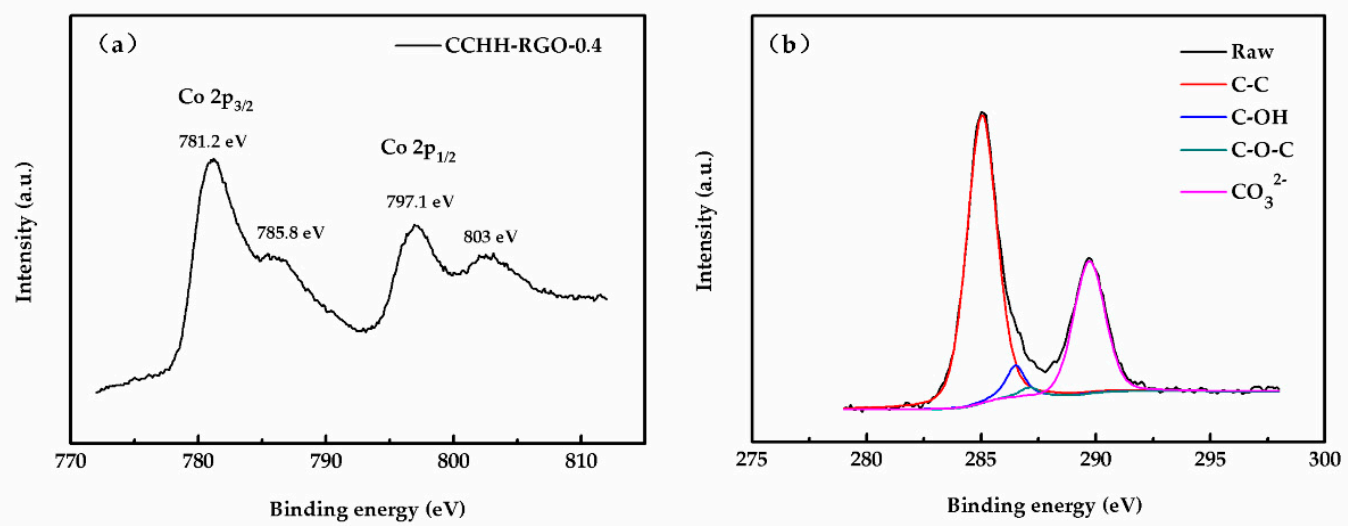

Figure 4. (a) XPS spectrum of the Co 2p composite; (b) XPS spectrum of the C 1s composite.

\subsection{Sensing Performance}

In order to study the gas sensing properties of CCHH and RGO hybrid sensors, a series of gas sensing tests were implemented in the proposed self-made test system at six different concentrations of ammonia at room temperature. The resistance values of several sensors changed with the injection and discharge of ammonia. The gas sensing response can be obtained as follow equation. 


$$
\text { Response }(\%)=\frac{R_{\mathrm{ammonia}}-R_{\mathrm{air}}}{R_{\mathrm{air}}} \times 100 \%
$$

$R_{a m m o n i a}$ and $R_{a i r}$ are the electrical resistance values with and without ammonia gas, respectively. The gas sensing response is defined as a ratio expressed in percentage.

As the ammonia gas in, the response curves of sensors began to increase rapidly and then slowly stabilized at a fixed maximum. Next, the response values decreased rapidly and returned to near the initial value after ammonia gas off. The black, red, blue and green curves correspond to the responses of four sensors (named RGO, CCHH-RGO-16, CCHH-RGO-4 and CCHH-RGO-0.4) to six concentrations of ammonia gas $(1,2.5,5,10,25,50 \mathrm{ppm})$ in Figure 5. In addition to these four sensors, the gas sensing responses of the remaining two sensors named CCHH and CCHH-RGO-0.1 were not given in the manuscript but provided in as shown in Figure S1 and Figure S2 in the SM. The base resistance values of these two sensors (more than $100 \mathrm{M} \Omega$ ) leaded to the signal current entering nanoampere level, bringing two fatal flaws. One of them, such a low signal current would cause the influence of background noise to increase dramatically and greatly interfere with the test results. Another, this level of signal current requires ultra-high precision in the test equipment, which meant a significant increase in signal processing circuit costs.

Figure 5 illustrated the gas sensing responses of four sensors at different ammonia concentrations. The gas sensing responses of these sensors gradually increased with the ammonia concentration and tended to be saturated and did not continue to increase when the ammonia concentration reached a higher value. As it could be seen clearly from the response curves, the response of RGO exhibited the lowest value, CCHH-RGO-4 exhibited higher value than CCHH-RGO-16, while CCHH-RGO-0.4 showed the highest response compared to the other three sensors. From the test results, the gas sensing response of the sensor to ammonia gas increased with the decrease of RGO mass proportion in the hybrid structure. When the RGO mass proportion reached $0.4 \%$, the gas sensing response was highest. As the RGO proportion continued to decrease, it would be very difficult to conduct gas test due to the great resistivity of the sensor such as CCHH and CCHH-RGO-0.1.

(a)

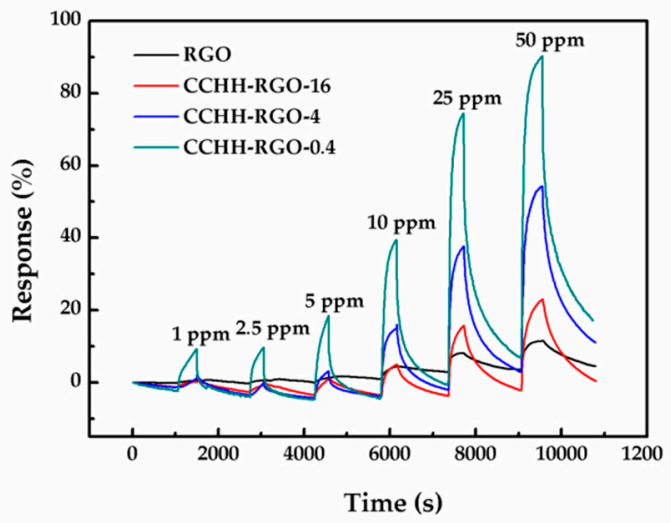

(b)

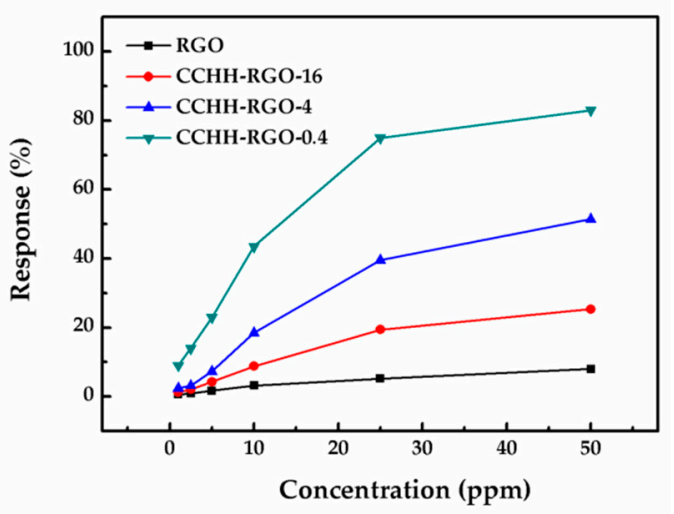

Figure 5. (a) Gas sensing response of four sensors under six different concentrations of ammonia; (b) Response with different concentrations of ammonia ranging from 1 to $50 \mathrm{ppm}$.

To study the gas sensing mechanism of the hybrid structure sensor, we performed a gas sensing test on the $10 \mathrm{ppm}$ ammonia gas for four sensors with a gas on (360 s)/gas off (1200 s) cycle of $1560 \mathrm{~s}$ at the same time. Figure 6a showed the gas sensing curves of four sensors to $10 \mathrm{ppm}$ ammonia. The gas sensing response, response time and recovery time of each sensor were shown in Figure $6 \mathrm{~b}$. RGO showed the lowest response (3.5\%), the longest response time (272 s) and the longest recovery time (895 s). The gas sensing response increased, the response time and the recovery time decreased with the decrease of RGO mass proportion in the hybrid structure. When the RGO mass proportion 
reaches $0.4 \%$, CCHH-RGO-0.4 showed the highest response (43.7\%), the least response time (184 s) and the least recovery time ( $575 \mathrm{~s}$ ) toward $10 \mathrm{ppm}$ ammonia.

Similar to metal oxide, there were a large number of lattice defects, surface discontinuities and a certain concentration of electron donor and acceptor energy levels on the surface of $\mathrm{CCHH}$, which could exchange electrons with oxygen molecules in the air to form oxygen anions $\left(\mathrm{O}_{2}^{-}\right)$at room temperature and conduct charge on the surface with the formation of space charge layer or space depletion region [27].

When ammonia gas reacted with the oxygen anion on the surface, ammonia molecules would release an electron to form ammonium ions. While the electron could be smoothly transferred to the surface of $\mathrm{CCHH}$ and then further diverted to RGO due to coupling effect between CCHH and RGO, which could give rise to the resistivity increase of the sensor owing to the prepared RGO being p-type material. Once the ammonia gas was removed, the ammonium ions would be converted to ammonia molecules and the resistivity of the sensor would decrease. Besides, $\mathrm{CCHH}$ prepared in this experiment was a sisal-like structure with a high specific surface area and the structure was conducive to the gas sensing response increase because the sisal-like structure was suitable for gas circulation.

The introduction of RGO greatly reduced the resistivity of the sensor due to the high conductivity of RGO, which not only facilitated the electronic conduction of the sensor after adsorbing gases but also increased the signal current to improve SNR and weaken the effect of noise. $\mathrm{CCHH}$ covered with RGO could sense tiny charge changes from adsorbed gases and provide a basis for realizing room temperature gas sensing tests. However, the proportion of RGO was not the more the better. The experimental results showed that with the increase of RGO proportion, the response of the sensor decreased gradually. The main reason may be that excessive RGO covered the surface of $\mathrm{CCHH}$, which prevented the gas molecules from reacting with the $\mathrm{CCHH}$, thus preventing the change of conductivity.
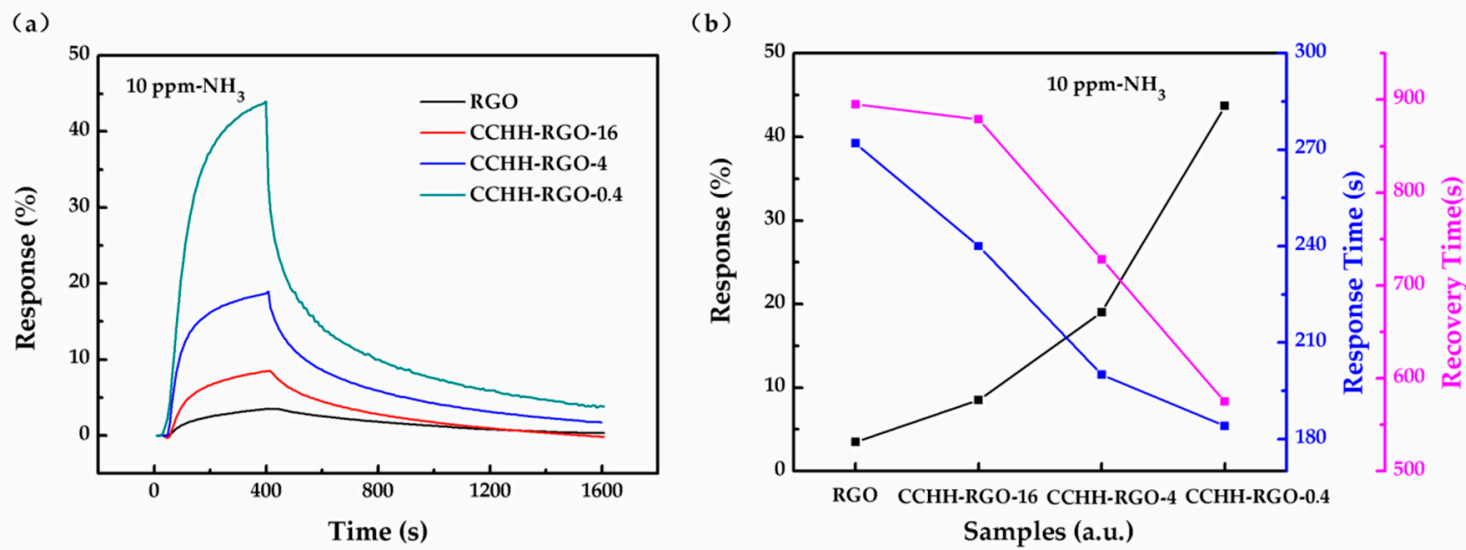

Figure 6. (a) Gas sensing response curve of four sensors to 10 ppm ammonia; (b) Gas sensing response, response time and recovery time of four sensors for $10 \mathrm{ppm}$ ammonia.

The exposure of the CCHH-RGO-0.4 to four continuous cycles of $10 \mathrm{ppm}$ ammonia was shown in Figure 7a. The sensor showed approximately the same response value and the response/recovery time, revealing its excellent repeatability under room temperature. In order to test the selectivity of the sensor to ammonia gas (10 ppm), four other kinds of $100 \mathrm{ppm}$ gases were tested under exactly the same test conditions, including acetone, isopropanol, ethanol and formaldehyde shown in Figure $7 \mathrm{~b}$. The device responded slightly to acetone and formaldehyde but hardly to isopropanol and ethanol. However, in sharp contrast, the device showed a very high response to ammonia, suggesting the strong selectivity of CCHH-RGO-0.4 towards ammonia. 
(a)

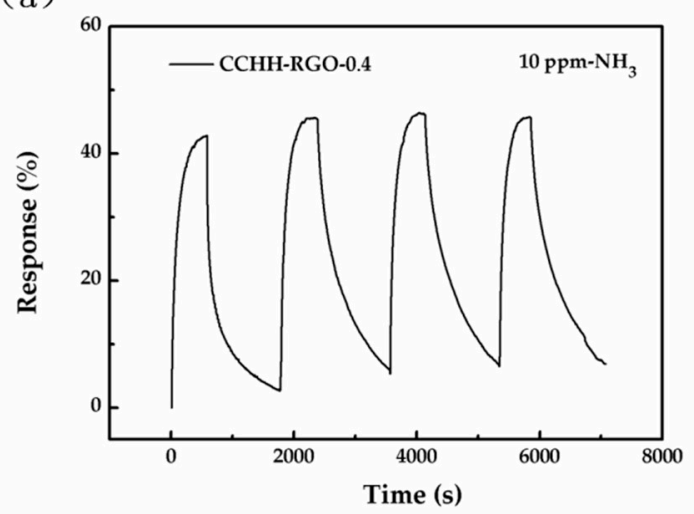

(b)

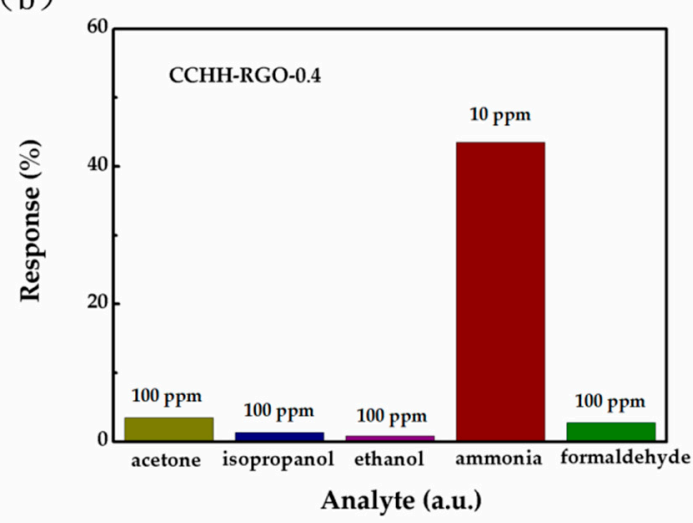

Figure 7. (a) Gas sensing response of the gas sensor after four continuous cycles under 10 ppm ammonia; (b) Selectivity response when exposed to acetone, isopropanol, ethanol, ammonia and formaldehyde.

There were several performance comparisons of different sensors reported by other journals. The sensing material, operating temperature, gas concentration and response of those sensors were listed in Table 2. $\mathrm{Ag} / \mathrm{ZnO}$ and $\mathrm{Pt} / \mathrm{SnO}_{2}$ as the sensing materials, could obtain a good gas sensing response at a high operating temperature. Although the remaining four sensing materials could be used for gas sensors at room temperature, their gas sensing responses were relatively low. Compared with these sensors, the proposed sensor in this paper with the simple fabrication process, not only could achieve gas sensing test at room temperature but also had excellent gas sensing performances.

Table 2. Comparison of various indicators between different ammonia sensors.

\begin{tabular}{ccccc}
\hline Materials & Temperature $\left({ }^{\circ} \mathbf{C}\right)$ & Concentration $(\mathbf{p p m})$ & Response (\%) & Reference \\
\hline $\mathrm{Ag} / \mathrm{ZnO}$ & 150 & 10 & 29.5 & {$[28]$} \\
$\mathrm{Pt} / \mathrm{SnO}_{2}$ & 115 & 50 & 25 & {$[29]$} \\
$\mathrm{RGO} / \mathrm{Graphene}_{\mathrm{PANI} / \mathrm{SnO}_{2}}^{25}$ & 25 & 0.5 & 2.88 & {$[30]$} \\
$\mathrm{Modified}-\mathrm{CNT}$ & 25 & 10 & 5 & {$[31]$} \\
$\mathrm{Graphene} / \mathrm{TiO}_{2}$ & 25 & 1.5 & 0.65 & {$[32]$} \\
$\mathrm{CCHH} / \mathrm{RGO}$ & 25 & 5 & 1.25 & {$[33]$} \\
\hline
\end{tabular}

\section{Conclusions}

In summary, the paper propose a novel CCHH-RGO gas sensor fabricated by a by one-step hydrothermal method. The simple synthesis not only simplified the experimental process but also facilitates mass production. The prepared sisal-like $\mathrm{CCHH}$ with high specific surface area could provide abundant gas adsorption interface and a suitable pathway for gas molecules. Meanwhile, the synthesized RGO uniformly dispersed on $\mathrm{CCHH}$ surface significantly improved the signal current and gas sensitivity caused by gas molecular adsorption. When the mass proportion of RGO was $0.4 \%$, CCHH-RGO hybrid structure had the optimized gas sensing response, reach to $9 \%$ to $1 \mathrm{ppm}$ ammonia. In addition, it could be found that CCHH-RGO hybrid structure had a good selectivity to ammonia by comparing several different gases as acetone, isopropanol, ethanol and formaldehyde. We believe that the novel hybrid sensor has the potential to be used in mass-produced gas sensors and is valuable for the future research on gas sensors.

Supplementary Materials: The following are available online at http:/ /www.mdpi.com/1424-8220/19/3/615/s1, Figure S1: Gas sensing (a) Response, (b) Resistance response, (c) Signal current response of CCHH to different concentrations of ammonia. Figure S2: Gas sensing (a) Response, (b) Resistance response, (c) Signal current response of CCHH-RGO-0.1 to different concentrations of ammonia. 
Author Contributions: C.W. designed the study project and experiments, collected and analyzed the data and wrote the paper. H.W., D.Z. and X.W. conducted experiments and collected data. X.L. provided funds and guidance on research ideas, analyzed the data and revised the paper. W.L. and H.L. provided guidance and gave advice on the experiments.

Funding: This research was funded by the Science and Technology Planning Project of Guangdong Province, National Natural Science Foundation of China, Shaanxi Natural Science Foundation, Science and Technology Planning Project of Zhejiang Province and grant number No. 2017A010103004, 91123018, 51625504, 61671368, 2014JM7277 and 2017C31087, respectively.

Acknowledgments: This work was financially supported by grants from Science and Technology Planning Project of Guangdong Province, China (2017A010103004) and the National Natural Science Foundation of China (No. 91123018, 51625504, 61671368), Shaanxi Natural Science Foundation (2014JM7277), Science and Technology Planning Project of Zhejiang Province, China (2017C31087). Some XPS work was done at International Center for Dielectric Research (ICDR), Xi'an Jiaotong University, Xi'an, China; Authors also thank Dai and Yang for their help in using XPS.

Conflicts of Interest: The authors declare that there is no conflict of interests regarding the publication of this study.

\section{References}

1. Comini, E.; Faglia, G.; Sberveglieri, G.; Pan, Z.W.; Wang, Z.L. Stable and highly sensitive gas sensors based on semiconducting oxide nanobelts. Appl. Phys. Lett. 2002, 81, 1869-1871. [CrossRef]

2. Liu, Y.; Koep, E.; Liu, M.L. Highly sensitive and fast-responding $\mathrm{SnO}_{2}$ sensor fabricated by combustion chemical vapor deposition. Chem. Mater. 2005, 17, 3997-4000. [CrossRef]

3. Moon, C.S.; Kim, H.R.; Auchterlonie, G.; Drennan, J.; Lee, J.H. Highly sensitive and fast responding CO sensor using $\mathrm{SnO}_{2}$ nanosheets. Sens. Actuator B Chem. 2008, 131, 556-564. [CrossRef]

4. Xu, P.C.; Cheng, Z.X.; Pan, Q.Y.; Xu, J.Q.; Xiang, Q.; Yu, W.J.; Chu, Y.L. High aspect ratio $\operatorname{In}_{2} \mathrm{O}_{3}$ nanowires: Synthesis, mechanism and $\mathrm{NO}_{2}$ gas-sensing properties. Sens. Actuator B Chem. 2008, 130, 802-808. [CrossRef]

5. Wang, B.; Zhu, L.F.; Yang, Y.H.; Xu, N.S.; Yang, G.W. Fabrication of a $\mathrm{SnO}_{2}$ nanowire gas sensor and sensor performance for hydrogen. J. Phys. Chem. C 2008, 112, 6643-6647. [CrossRef]

6. Wagh, M.S.; Jain, G.H.; Patil, D.R.; Patil, S.A.; Patil, L.A. Modified zinc oxide thick film resistors as $\mathrm{NH}_{3}$ gas sensor. Sens. Actuator B Chem. 2006, 115, 128-133. [CrossRef]

7. Zhang, J.; Wang, S.R.; Xu, M.J.; Wang, Y.; Zhu, B.L.; Zhang, S.M.; Huang, W.P.; Wu, S.H. Hierarchically Porous ZnO Architectures for Gas Sensor Application. Cryst. Growth Des. 2009, 9, 3532-3537. [CrossRef]

8. Chen, M.; Wang, Z.H.; Han, D.M.; Gu, F.B.; Guo, G.S. Porous ZnO Polygonal Nanoflakes: Synthesis, Use in High-Sensitivity $\mathrm{NO}_{2}$ Gas Sensor, and Proposed Mechanism of Gas Sensing. J. Phys. Chem. C 2011, 115, 12763-12773. [CrossRef]

9. Cuong, T.V.; Pham, V.H.; Chung, J.S.; Shin, E.W.; Yoo, D.H.; Hahn, S.H.; Huh, J.S.; Rue, G.H.; Kim, E.J.; Hur, S.H.; et al. Solution-processed ZnO-chemically converted graphene gas sensor. Mater. Lett. 2010, 64, 2479-2482. [CrossRef]

10. Yi, J.; Lee, J.M.; Park, W., II. Vertically aligned $\mathrm{ZnO}$ nanorods and graphene hybrid architectures for high-sensitive flexible gas sensors. Sens. Actuator B Chem. 2011, 155, 264-269. [CrossRef]

11. Jiang, Z.X.; Li, J.; Aslan, H.; Li, Q.; Li, Y.; Chen, M.L.; Huang, Y.D.; Froning, J.P.; Otyepka, M.; Zboril, R.; et al. A high efficiency $\mathrm{H}_{2} \mathrm{~S}$ gas sensor material: Paper like $\mathrm{Fe}_{2} \mathrm{O}_{3}$ /graphene nanosheets and structural alignment dependency of device efficiency. J. Mater. Chem. A 2014, 2, 6714-6717. [CrossRef]

12. Jie, X.Q.; Zeng, D.W.; Zhang, J.; Xu, K.; Wu, J.J.; Zhu, B.K.; Xie, C.S. Graphene-wrapped $W_{3}$ nanospheres with room-temperature $\mathrm{NO}_{2}$ sensing induced by interface charge transfer. Sens. Actuator B Chem. 2015, 220, 201-209. [CrossRef]

13. Hassan, M.; Wang, Z.H.; Huang, W.R.; Li, M.Q.; Liu, J.W.; Chen, J.F. Ultrathin Tungsten Oxide Nanowires/Reduced Graphene Oxide Composites for Toluene Sensing. Sensors 2017, 17, 2245. [CrossRef] [PubMed]

14. Chatterjee, S.G.; Chatterjee, S.; Ray, A.K.; Chakraborty, A.K. Graphene-metal oxide nanohybrids for toxic gas sensor: A review. Sens. Actuator B Chem. 2015, 221, 1170-1181. [CrossRef]

15. Xia, Y.; Li, R.; Chen, R.S.; Wang, J.; Xiang, L. 3D Architectured Graphene/Metal Oxide Hybrids for Gas Sensors: A Review. Sensors 2018, 18, 1456. [CrossRef] [PubMed]

16. Li, X.G.; Zhao, Y.Y.; Wang, X.Y.; Wang, J.; Gaskov, A.M.; Akbar, S.A. Reduced graphene oxide (rGO) decorated $\mathrm{TiO}_{2}$ microspheres for selective room-temperature gas sensors. Sens. Actuator B Chem. 2016, 230, 330-336. [CrossRef] 
17. Feng, Q.X.; Li, X.G.; Wang, J. Percolation effect of reduced graphene oxide (rGO) on ammonia sensing of rGO-SnO 2 composite based sensor. Sens. Actuator B Chem. 2017, 243, 1115-1126. [CrossRef]

18. Liu, Z.Y.; Yu, L.M.; Guo, F.; Liu, S.; Qi, L.J.; Shan, M.Y.; Fan, X.H. Facial development of high performance room temperature $\mathrm{NO}_{2}$ gas sensors based on $\mathrm{ZnO}$ nanowalls decorated rGO nanosheets. Appl. Surf. Sci. 2017, 423, 721-727. [CrossRef]

19. Ha, N.H.; Thinh, D.D.; Huong, N.T.; Phuong, N.H.; Thach, P.D.; Hong, H.S. Fast response of carbon monoxide gas sensors using a highly porous network of $\mathrm{ZnO}$ nanoparticles decorated on 3D reduced graphene oxide. Appl. Surf. Sci. 2018, 434, 1048-1054. [CrossRef]

20. Liu, J.; Li, S.; Zhang, B.; Xiao, Y.; Gao, Y.; Yang, Q.Y.; Wang, Y.L.; Lu, G.Y. Ultrasensitive and low detection limit of nitrogen dioxide gas sensor based on flower-like $\mathrm{ZnO}$ hierarchical nanostructure modified by reduced graphene oxide. Sens. Actuator B Chem. 2017, 249, 715-724. [CrossRef]

21. Zhang, Y.X.; Xiao, Q.Q.; Guo, X.; Zhang, X.X.; Xue, Y.F.; Jing, L.; Zhai, X.; Yan, Y.M.; Sun, K.N. A novel electrocatalyst for oxygen evolution reaction based on rational anchoring of cobalt carbonate hydroxide hydrate on multiwall carbon nanotubes. J. Power Sources 2015, 278, 464-472. [CrossRef]

22. Fang, D.; Li, L.C.; Xu, W.L.; Li, G.Z.; Li, G.; Wang, N.F.; Luo, Z.P.; Xu, J.; Liu, L.; Huang, C.L.; et al. Self-assembled hairy ball-like $\mathrm{Co}_{3} \mathrm{O}_{4}$ nanostructures for lithium ion batteries. J. Mater. Chem. A 2013, 1, 13203-13208. [CrossRef]

23. Xiao, Y.H.; Liu, S.J.; Li, F.; Zhang, A.Q.; Zhao, J.H.; Fang, S.M.; Jia, D.Z. 3D Hierarchical $\mathrm{Co}_{3} \mathrm{O}_{4}$ Twin-Spheres with an Urchin-Like Structure: Large-Scale Synthesis, Multistep-Splitting Growth, and Electrochemical Pseudocapacitors. Adv. Funct. Mater. 2012, 22, 4052-4059. [CrossRef]

24. Needham, S.A.; Wang, G.X.; Konstantinov, K.; Tournayre, Y.; Lao, Z.; Liu, H.K. Electrochemical performance of $\mathrm{Co}_{3} \mathrm{O}_{4}-\mathrm{C}$ composite anode materials. Electrochem. Solid St. 2006, 9, A315-A319. [CrossRef]

25. Schenck, C.V.; Dillard, J.G.; Murray, J.W. Surface-Analysis And the Adsorption Of Co(Ii) on Goethite. J. Colloid Interface Sci. 1983, 95, 398-409. [CrossRef]

26. Varghese, B.; Hoong, T.C.; Yanwu, Z.; Reddy, M.V.; Chowdari, B.V.R.; Wee, A.T.S.; Vincent, T.B.C.; Lim, C.T.; Sow, C.H. $\mathrm{Co}_{3} \mathrm{O}_{4}$ nanostructures with different morphologies and their field-emission properties. Adv. Funct. Mater. 2007, 17, 1932-1939. [CrossRef]

27. Kim, H.J.; Lee, J.H. Highly sensitive and selective gas sensors using p-type oxide semiconductors: Overview. Sens. Actuator B Chem. 2014, 192, 607-627. [CrossRef]

28. Ganesh, R.S.; Navaneethan, M.; Patil, V.L.; Ponnusamy, S.; Muthamizhchelvan, C.; Kawasaki, S.; Patil, P.S.; Hayakawa, Y. Sensitivity enhancement of ammonia gas sensor based on $\mathrm{Ag} / \mathrm{ZnO}$ flower and nanoellipsoids at low temperature. Sens. Actuator B Chem. 2018, 255, 672-683.

29. Liu, X.; Chen, N.; Han, B.Q.; Xiao, X.C.; Chen, G.; Djerdj, I.; Wang, Y.D. Nanoparticle cluster gas sensor: Pt activated $\mathrm{SnO}_{2}$ nanoparticles for $\mathrm{NH}_{3}$ detection with ultrahigh sensitivity. Nanoscale 2015, 7, 14872-14880. [CrossRef]

30. Wang, C.; Lei, S.C.; Li, X.; Guo, S.X.; Cui, P.; Wei, X.Q.; Liu, W.H.; Liu, H.Z. A Reduced GO-Graphene Hybrid Gas Sensor for Ultra-Low Concentration Ammonia Detection. Sensors 2018, 18, 3147. [CrossRef]

31. Bai, S.L.; Tian, Y.L.; Cui, M.; Sun, J.H.; Tian, Y.; Luo, R.X.; Chen, A.F.; Li, D.Q. Polyaniline@SnO 2 heterojunction loading on flexible PET thin film for detection of $\mathrm{NH}_{3}$ at room temperature. Sens. Actuator $B$ Chem. 2016, 226, 540-547. [CrossRef]

32. Panes-Ruiz, L.A.; Shaygan, M.; Fu, Y.X.; Liu, Y.; Khavrus, V.; Oswald, S.; Gemming, T.; Baraban, L.; Bezugly, V.; Cuniberti, G. Toward Highly Sensitive and Energy Efficient Ammonia Gas Detection with Modified Single-Walled Carbon Nanotubes at Room Temperature. ACS Sens. 2018, 3, 79-86. [CrossRef] [PubMed]

33. Ye, Z.B.; Tai, H.L.; Guo, R.; Yuan, Z.; Liu, C.H.; Su, Y.J.; Chen, Z.; Jiang, Y.D. Excellent ammonia sensing performance of gas sensor based on graphene/titanium dioxide hybrid with improved morphology. Appl. Surf. Sci. 2017, 419, 84-90. [CrossRef]

(C) 2019 by the authors. Licensee MDPI, Basel, Switzerland. This article is an open access article distributed under the terms and conditions of the Creative Commons Attribution (CC BY) license (http:/ / creativecommons.org/licenses/by/4.0/). 